\title{
Letters
}

Website: bmj.com

Email: letters@bmj.com

\section{Priority setting in health care}

\section{Of course we should ask the tax payer}

EDITOR-Torgerson and Gosden argue that eliciting public views on healthcare priority setting is a waste of money. ${ }^{1}$ It is implicit in their argument that the many health economists who dabble in this allegedly inefficient activity should know better. As health economists and practitioners of the dark art of including the public in priority setting, we believe that we ought to respond to this charge.

The problem with Torgerson and Gosden's argument is that it does not distinguish between facts and values. It seems reasonable to assume that patients normally know less than clinicians about the facts concerning the effects of different treatments. As Torgerson and Gosden argue, this form of asymmetric information is one reason why many British health economists believe that public funding of health care is more efficient than private funding, which provides clinicians with a profit motive for supplying unnecessary treatments to illinformed patients.

Torgerson and Gosden assert that patients generally know less than specialists about the "facts" concerning the effects of

\section{Advice to authors \\ We prefer to receive all responses electronically, sent either directly to our website or to the editorial office as email or on a disk. Processing your letter will be delayed unless it arrives in an electronic form. \\ We are now posting all direct submissions to our website within 24 hours of receipt and our intention is to post all other electronic submissions there as well. All responses will be eligible for publication in the paper journal. \\ Responses should be under 400 words and relate to articles published in the preceding month. They should include $\leqslant 5$ references, in the Vancouver style, including one to the BMJ article to which they relate. We welcome illustrations. \\ Please supply each author's current appointment and full address, and a phone or fax number or email address for the corresponding author. We ask authors to declare any competing interest. Please send a stamped addressed envelope if you would like to know whether your letter has been accepted or rejected. \\ Letters will be edited and may be shortened. \\ bmj.com \\ letters@bmj.com}

alternative priority setting decisions, and they conclude that setting priorities on the basis of ill-informed opinions is inefficient. What Torgerson and Gosden do not recognise, however, is the possibility that patients generally know more than specialists about their own values concerning their health and the health of others.

This kind of asymmetrical information can lead well meaning clinicians, managers, and policymakers to provide inefficient healthcare services, poorly in tune with patients' values. That is why health economists have devoted considerable energy to developing methods of valuing the effects of treatments from the patient's point of view. That is also why health economists are now devoting energy to developing methods of consulting patients about their values concerning priority setting.

Asymmetrical information about facts can cause inefficiency in a private system, which is why we need a public system. Asymmetrical information about values can cause inefficiency in a public system, which is why we need to include the public in healthcare priority setting. Efficient decision making requires the use of best available information about facts and values. Our experience in conducting preference elicitation studies suggests that asking the taxpayer can be a fruitful source of information about the latter-and that public opinions are more sophisticated, and less predictable, than Torgerson and Gosden like to think.

Richard Cookson senior lecturer in health economics School of Health Policy and Practice, University of East Anglia, Norwich NR4 7TJ

Paul Dolan reader in health economics

School of Health and Related Research and Department of Economics, University of Sheffield, Sheffield S1 4DA

1 Torgerson D, Gosden T. Priority setting in health care:
should we ask the tax payer? BMJ 2000;320:1679. (17 June.)

\section{Claims are not supported in research literature}

EDITOR-Torgerson and Gosden's personal view is that ascertaining the public's view on resource allocation is inefficient. ${ }^{1}$ It would have been useful for them to have supported their claims by reference to the evidence base as we have found no support in the research literature for a number of their statements.

Torgerson and Gosden state, for example, that questionnaire surveys show that smokers, drug users, heavy drinkers, and elderly people should receive lower priority than other people. We have conducted a review of recent research on this subject and found, in contrast, widespread support for the principle of equity, a strong view that elderly people should not be treated differently from anyone else and, with the exception of services for drug misusers, an abhorrence for limiting treatment on the basis of cause of illness.

Torgerson and Gosden also argue that as the public are unlikely to be able to ration healthcare delivery to the population efficiently then resources could be diverted into popular medical procedures that at best might be effective, but horrendously expensive, and at worst expensive and harmful. However, research undertaken by the Consumer Council found that the public's highest priority for funding, after beds and staffing, was health promotion and helping people to help themselves. ${ }^{3}$ It seems that prevention being better than cure is one principle you do not have to be a health economist to understand. In this study the public were also acutely aware of the importance to health of underlying issues, such as employment and the quality of education, more so perhaps than some health economists.

Jon Ford head

Lorelei Cooke research officer

lcooke@bma.org.uk

Health Policy and Economic Research Unit, BMA House, London WC1H 9JP

1 Torgerson D, Gosden T. Priority setting in health care: should we ask the tax payer? BMJ 2000;320:1679. (17 June.)

2 Health Policy and Economic Research Unit. Review of UK healthcare funding. Research report 1-What sort of healthcare does the public expect, want or need? London: BMA, 2000.

3 National Consumer Council. Consumer concerns 1998-A consumer view of health services, the report of an RSL survey. London: National Consumer Council, 1998.

\section{Authors' reply}

EDIToR-Cookson and Dolan confuse the subject we raised by introducing healthcare evaluation issues with which we largely agree and that we will not discuss further. Ascertaining public priorities would be a harmless activity if two conditions were fulfilled: first, they were not used in a priority setting; second, they incurred no opportunity cost. The first condition is largely fulfilled, but the second is not. There is a cost to estimating public preferences as witnessed by the $£ 500000$ the government spent on a large survey recently, the opportunity cost of which is about 100 hip replacements. Thus, scarce resources are, in our opinion, being wasted. Even if "democratic" participation in 
healthcare decision making were useful the response rates to surveys can be very low.

For example, Cookson and Dolan's own work, in which they had used focus groups, found that only $17 \%$ of the population prepared to attend a meeting (despite being paid £30)-this is hardly representative. ${ }^{1} \mathrm{We}$ are not sure how the "fruitful" results of their work are to be applied to priority setting. Should paediatric services be expanded and the cost be met by reducing services for illegal drug users and smokers as their work suggests? If not, what was the point of eliciting the priorities? Cookson and Dolan also distinguish between values and facts, but the two aspects are interrelated. The public may "value" a healthcare procedure highly but based on factually incorrect information. The decision to prioritise children may be based on factually incorrect information that treatments are more effective than is the case because successful paediatric treatments hold the media's attention more so than effective treatments for elderly people.

Ford and Cooke argue that our perceptions of patient surveys are mistaken. We accept that our exposure is to a limited amount of work (for example, Dolan et al and Bowling'). Ford and Cooke confirm, however, that drug misusers have a low priority. Predictably the public would like more money spent on prevention: more screening for breast cancer, perhaps? Breast screening has little basis in evidence and was largely introduced by the last administration in response to yet another "NHS crisis." A less glamorous preventive strategy of screening for colorectal cancer has not yet been introduced (because of little public pressure?) despite trials showing it to be effective and cost effective. ${ }^{4}$ With respect to employment and education, most health economists, ourselves included, will agree that such things influence health much more than direct health care.

David Torgerson senior research fellow Centre for Health Economics and Department of Health Studies, University of York, York YO10 5DD Toby Gosden research fellow

National Primary Care Research and Development Centre, University of Manchester, Manchester M13 9PL

1 Dolan P, Cookson R, Ferguson B. Effect of discussion and deliberation on the public's views of priority setting in health care: focus group study. BMJ 1999;318:916-19.

2 Bowling A. Health care rationing: the public's debate. BMJ Bowling A. Heal

1996;312:670-4.
Gøtzsche PC Olsen O Is screening for breast cancer with

3 Gøtzsche PC, Olsen O. Is screening for breast cance
mammography justifiable? Lancet 2000;355:129-34.

mammography justifiable? Lancet 2000;355:129-34.
4 Hardcastle JD, Chamberlain JO, Robinson MH, Moss SM,

4 Hardcastle JD, Chamberlain JO, Robinson MH, Moss SM,
Amar SS, Balfour TW, et al. Randomised controlled trial of faecal-occult-blood screening for colorectal cancer. Lancel 1996;348:1472-7.

\section{Family histories of cancer in primary care}

\section{Referrals might be made on the basis of women's anxiety}

EDITOR-I read with interest the paper by Emery et al on using different methods of assessing genetic risk for breast and ovarian cancer and also the previous paper by
Emery with a different set of coauthors. ${ }^{12}$ In both these papers the authors assume that general practitioners have the time and will to take on new responsibilities and skills. Emery et al state that only three of the 36 general practitioners in the study were able to find the paper management guidelines for referral. ${ }^{1}$ It is hard to imagine that they are first going to find the computer software, remember how to use it, and then remember how to interpret the results during a five minute appointment. They cannot then just refer to a specialist or not; they would have to give some form of counselling-another new skill to learn and remember. There is evidence to suggest that general practitioners are reluctant to take on these new roles.

Emery et al assume that the aim is to try to stop unnecessary referrals to genetic clinics. Most referrals are made to local breast units, of which there are more than 100 in the country doing family history screening, whose staff are used to discussing the risks of and necessity for screening. In our breast unit we send a questionnaire to patients referred because of a family history risk, asking for details of their relatives, and then only see the ones who meet guidelines for screening. We send a detailed letter to the others explaining why their risk is low; patients at very high risk are referred on to the genetics service. This allows general practitioners to refer women to us on the basis of their anxiety and their own perceived risk rather than their actual risk, and saves doctors from having to find a piece of paper with rather complicated guidelines or a computer programme which they have forgotten how to use. A study of this evaluation method (submitted for publication) has shown that we end up seeing $50 \%$ of the patients referred, the other $50 \%$ at low or no elevated risk being very satisfied with the method.

M H Shere clinical assistant

Breast Care Centre, Frenchay Hospital, Bristol BS16 1ND

mike.shere@north-bristol.swest.nhs.uk

1 Emery J, Walton R, Murphy M, Austoker A, Yudkin P, Chapman C, et al. Computer support for interpretin amily histories of breast and ovarian cancer in primary care: comparative study with simulated cases. $B M$ 2000;321:28-32. (1 July)

2 Emery J, Walton R, Coulson A, Glasspool D, Ziebland S, Fox J Computer support for recording and interpreting family histories of breast and ovarian cancer in primary fare (RAG): quatitative and ovarian cancer in primary care (RAGs): qualit

3 Kumar S, Cantley M Tensions between policy makers and Kumar S, Gantley M. Tensions between policy makers an general practitioners in implementing new genetic.
grounded theory interview study. BMJ 1999;319:1410-3.

\section{Nurse led clinic may provide better service than computer program}

EDITOR-We welcome the development of tools to aid the assessment of genetic risk in primary care, as reported by Emery et al in their paper, ${ }^{1}$ but we do not believe that general practitioners are ideally placed to provide the counselling and reassurance required for patients at perceived extra risk of developing breast cancer.

We have developed a family history clinic led by a nurse, to which general practitioners can refer all patients concerned about their cancer risk. The nurse underwent training in the regional cancer genetics centre. Before their appointment, patients are given time to look into their family history in more detail so that an accurate pedigree can be drawn up and a risk group assigned. This clinic has the advantage of providing reassurance and accurate advice within the environment of a specialist local clinic in an unhurried atmosphere.

Patients at low risk often need as much explanation and advice as those at higher risk. The selected subgroup of patients at high risk can be referred to the regional cancer genetics centre, if they wish. Patients at moderate risk can be advised of appropriate trials of screening. Referrals can be made by any general practitioner who feels he or she lacks the wherewithal to advise patients. In addition to providing specialist advice at a local level this clinic has also reduced the burden of referrals to the regional cancer genetics centre. Overall we believe that this provides a better service than a general practitioner armed with a computer program.

Emma Gray specialist registrar general surgery

Neil Rothnie consultant breast surgeon

Amanda Fowler clinic sister

Southend Breast Unit, Southend Hospital,

Southend SSO ORY

1 Emery J, Walton R, Murphy M, Austoker A, Yudkin P, Chapman C, et al. Computer support for interpreting family histories of breast and ovarian cancer in primary care: comparative study with simulated cases. $B M$ 2000;321:28-32. (1 July.)

\section{Should asymptomatic haemochromatosis be treated?}

\section{Alternative strategies to appropriate diagnosis need testing}

EDITOR-The contributions by Seamark and Hutchinson on the role of testing for and treatment of hereditary haemochromatosis highlight important issues about this disease and more generally about the clinical application of new genetic discoveries. ${ }^{1}$ Uncertainties about the definition of disease are highlighted-should it be based on genotype, abnormal biochemistry, or symptoms, and, consequently, at what point does a predisposition to disease become genuine disease? This is a reflection more generally of the genetics of disease predisposition and the management of disease risk. Inevitably if we treat the risk of a disease-be it by venesection for raised concentrations of ferritin or with tamoxifen in women with a family history of breast cancer-only a proportion of patients will benefit and some will be harmed. ${ }^{2}$

We should be cautious about developing screening strategies for hereditary haemochromatosis for the general population. Proponents of population screening argue that it is common (based on a genetic definition of disease) and that prospective cohort studies show that early treatment results in normal life expectancy. ${ }^{3}$ For ethical reasons there will probably never be evidence from randomised controlled trials of venesection 
compared with watchful waiting in people with raised concentrations of ferritin. There is, however, sufficient uncertainty about expression of disease in C282Y homozygotes in the general population, and the role of gene/gene and gene/environment interaction in determining penetrance to postpone population screening until we know the results of large cohort studies of C282Y homozygotes from the general population.

In the meantime, primary care must still be aware of the possibility of misdiagnosing hereditary haemochromatosis and labelling patients with the diagnostic category of end stage disease such as cardiac failure or cirrhosis. The case of the patient $(\mathrm{MH})$ described could be an example of this and we question the title of "asymptomatic haemochromatosis." Her case also shows a potential role for general practitioners in supporting shared decision making in patients who have received a diagnosis of hereditary haemochromatosis, given the uncertainties about management. $\mathrm{MH}$ was diagnosed using a case finding approach to the diagnosis of haemochromatosis, and this has been proposed as a reasonable course of action while we wait the results of population studies of hereditary haemochromatosis. ${ }^{4}$ The cost effectiveness of early diagnosis of hereditary haemochromatosis through systematic case finding and the positive predictive value of specific symptoms or symptom clusters in primary care require further investigation. In this way we may be more likely to define a group of people with hereditary haemochromatosis who would benefit from their diagnosis.

Jon Emery Cancer Research Campaign primary care oncology research fellow

Imperial Cancer Research Fund General Practice Research Group, University of Oxford, Institute of Health Sciences, Oxford OX3 7LF

jon.emery@dphpc.ox.ac.uk

Peter Rose general practitioner

Mill Stream Surgery, Oxford OX10 6RL

1 Seamark C, Hutchinson M. Should asymptomatic haemochromatosis be treated? Treatment can be an onerous one [with commentaries by Heath and McMullin]. BM/ 2000;320:1314-7. (13 May)

2 Fisher B, Costantino JP, Wickerham DL, Redmond CK, Kavanah M, Cronin WM, et al. Tamoxifen for prevention of breast cancer: report of the National Surgical Adjuvant breast cancer: report of the National Surgical Adjuvan Breast and Bowel Project P-1 Study. J Natl Cancer Inst 1998;90(18):1371-88.

Allen K, Williamson R. Screening for hereditary haemohromatosis should be implemented now. BMJ 2000;320 183-4.

4 Burke W, Thomson E, Khoury MJ, McDonnell SM, Press N, Adams PC, et al. Hereditary hemochromatosis: gene discovery and its implications for population-based screening. JAMA 1998;280:172-8.

Consequences of screening must be made known

EDITOR-The contributions by Seamark and Hutchinson and the accompanying commentaries by Heath and McMullins raised some interesting points that could be extended to all screening programmes, both current and projected. ${ }^{1}$ The most important of these is the principle that people without symptoms need to have the consequences of being screened explained to them before the screening test. It is not entirely clear whether the patient described was actually aware of these consequences and, if she had been, whether she would have agreed so readily to undergo screening. Health professionals have a tendency to overstate the benefits of screening and to underplay the less welcome consequences of it. ${ }^{23}$ Although there are signs that this paternalistic attitude is changing, there is some way to go.

In the paper there seems to be a difference in emphasis between the two general practitioners and the hospital specialist. Both general practitioners seem to place more importance on the quality of life, whereas the specialist views the less tangible benefit of a serum concentration of ferritin that is within normal limits to be important The patient herself shares the attitude of the general practitioners and sees little benefit in being treated for a disease she may never have had any problem with and for which the treatment, in her view, is worse than the disease itself.

As screening tests become more sensitive there is a danger that many more individuals may encounter this problem. Screening tests are often described to the general public and politicians as the way forward. In reality the life expectancy gains achieved through screening may be less than is generally appreciated. Care must be taken that participants understand this before they undergo the tests, and not afterwards. The paper by Seamark and Hutchinson goes some way to redressing the balance.

John Nottingham consultant histopathologist George Eliot Hospital NHS Trust, College Street, Nuneaton, Warwickshire CV10 7DJ jfnottingham@doctors.org.uk

1 Seamakc, chromatosis be treated? M. Should asymptomatic haemochromatosis be treated? Treatment can be an onerous one [with commentaries by Heath and McMullin]. BMJ 2000;320:1314-7. (13 May.)

2 Thornton H, Baum M. Should a mammographic screening programme carry the warning: 'Screening can damage your health!'? Br J Cancer 1999;79:691-2.

Ness AR, Frankel SJ, Gunnell DJ, Davey Smith G. Are we really dying for a $\tan$ ? $B M J 1999 ; 319: 114-6$.

4 Austoker J. Gaining informed consent for screening. $B M J$ 1999;319:722-3.

\section{Update from Seamark and Hutchinson}

EDITOR-We used the term asymptomatic haemochromatosis as $\mathrm{MH}$ had no symptoms attributable to the condition and it would not have been found apart from the screening programme she took part in. She had no disturbance of liver function, no family history, her haemoglobin concentration was normal and there was no indication to check serum concentration of ferritin.

$\mathrm{MH}$ and her family have a strong sense of civic duty, hence their participation in diabetes research. This research did not specifically counsel about haemochromatosis, but when a potentially treatable condition was found it was decided that MH should be informed.

With regard to MH's family, her father was not known to have haemochromatosis although he did have diabetes. As $\mathrm{MH}$ is homozygous for $\mathrm{C} 282 \mathrm{Y}$ her father must have either been a carrier or had undiagnosed haemochromatosis. Her brother has diabetes, but does not have haemochromatosis (although he could be a carrier). One sister and her children have neither diabetes nor haemochromatosis, although the sister has had thyroid disease. MH's other sister does not have diabetes but has recently been diagnosed as having haemochromatosis. Despite knowing far more about the condition than MH did two years ago she is about to start venesection.

We both believe that possibly more explanation would have been helpful in the initial stages, and we have since been sent some useful booklets and videos. CS feels that it is not usually helpful to paint the worst picture for patients at the start of treatment and so only gradually let $\mathrm{MH}$ know that the treatment might take longer than initially hoped. $\mathrm{MH}$ would also like to clarify what she meant when she wrote "not letting my doctor down"; she really meant that she would have regretted wasting everyone's time, she was not trying to earn "Brownie points."

Two years on we both feel more positive, and we meet less regularly for venesection and to talk about our travels and the paper. MH's latest serum concentration of ferritin was $30 \mu \mathrm{g} / 1$ (normal range $10-110 \mu \mathrm{g} / \mathrm{l}$ ). $\mathrm{MH}$ realises that the treatment is for life, but it is less intrusive and she plans to return to Ascension in 2001 and New Zealand in 2002

The aim of our paper was to promote discussion, which we have achieved, and to highlight that although venesection is safe and, some would say, easy, it does have important effects on the patient and staffing implications that should be taken into account if population screening for haemochromatosis is ever planned.

Clare J Seamark general practitioner

Margot Hutchinson retired headmistress

Honiton Group Practice, Marlpits Lane, Honiton, Devon EX14 2NY

\section{WHO and industry partnership}

\section{Changes to paper served to stifle debate}

EDITOR-As the author of the paper on strengthening the international code of marketing of breast milk substitutes for the meeting on infant feeding held by the World Health Organization and Unicef, I applaud Ferriman for bringing this matter to the attention of the public. ${ }^{1}$ One cannot help but wonder about the driving force behind the WHO's last minute cuts to papers prepared for the meeting.

The WHO asked me to write about successes for and obstacles to the implementation of the international code since its adoption in 1981, and to suggest a way forward. Before the meeting, the paper went through several drafts, and I had incorporated changes suggested by both the WHO and Unicef. Yet, at the meeting itself, the WHO cut nearly a third of the paper and did not circulate it to participants until the third day. 
One of the big obstacles to implementation of the code identified in the paper related to the marketing practices of infant food companies. The WHO deleted nearly all descriptions and criticisms of such practices as they have evolved over the 19 years since the code was adopted.

At the meeting, the WHO staff blamed the cuts on the organisation's legal department. I await a response to my request for a written legal rationale for each deletion in the paper. The explanation offered in the article by the WHO spokesperson, that the paper did not meet a high standard of scientific objectivity and balance, is new to me. It is difficult to see how objectivity and balance could be better achieved through omitting all discussion of marketing practices, which I described as one of the major obstacles to achieving the code's primary aim to protect and promote breast feeding.

The WHO and Unicef invited me to write this paper on the basis of my longstanding experience as legal adviser to a non-governmental organisation that focuses on implementation of the international code. Through my work I have helped in national implementation and observed marketing practices all over the world. The paper was meant to provide background to a group of experts for their discussions of how to strengthen the code as part of the WHO's and Unicef's overall strategy to improve the feeding of infants and young children. Suppressing details and explanations about company marketing activities could serve no purpose other than to stifle the debate.

Readers may wish to request a copy of the submitted draft from Graeme Clugston, director, Nutrition for Health and Development, WHO, and compare it with the draft that was circulated to participants.

Ellen Sokol consultant

PO Box 2303, Fort Myers Beach, FL 33932, USA ellensokol@hotmail.com

1 Ferriman A. WHO accused of stifling debate about infant feeding. BMJ 2000;320:1362. (20 May.)

\section{A question of standards?}

EdITOR-I refer to Ferriman's news article on the World Health Organization and infant feeding. ${ }^{1}$ As the author of one of the contested background papers for the technical consultation called by the WHO and Unicef, I would like to react to the statement by a WHO spokesperson that my paper failed to meet the agency's high standard of scientific objectivity and balance.

Our differences stem not so much from a variance of criteria in how to evaluate "scientific truth" but from a difference over what should-and, critically, what should notform part of a background paper on how globalisation affects infant feeding.

In the agreed terms of reference for the background paper, I proposed to explore whether the infant food industry should have a greater role in shaping national and global infant feeding policies or not. Part three of my paper deals with infant feeding and global democratic governance. It draws attention to issues management, a corporate public relations discipline that encompasses strategic sponsorships and partnerships to build up goodwill capital, which is regarded by transnational corporations as an invaluable resource to influence political and regulatory debates.

I concluded that infant food manufacturers should not be involved in policymaking on infant feeding. This conclusion was based on an analysis of infant food manufacturers' conduct in relation to their marketing practices, implementation of the international code of marketing of breast milk substitutes, and international public debates; and on concerns about a more general conflict between profit-making and public policymaking. I argued that the appropriate role of manufacturers of infant food is to deliver reasonably priced products of good quality and market them in ways that do not violate the code and subsequent resolutions.

My paper underwent two rounds of comments by Unicef and WHO. I was therefore surprised to learn on the eve of the consultation that WHO had unilaterally decided to cut eight pages, including the reasoned argument on which I had based the above conclusion. Moreover, the conclusion had been altered so that it no longer reflected my point of view. Critically, the anonymous editors left open the question of further industry involvement in global policymaking.

I do not see how these changes made my paper more objective or balanced. Instead, they seem to reflect the bias that any material that might suggest caution regarding the WHO's current drive towards "partnership" with industry is not suitable for discussion at a meeting whose main purpose was further to develop a strategy by WHO and Unicef for infant and young child feeding.

Judith Richter consultant

Wilhelmstrasse 174, D-72074 Tübingen, Germany richterjcl@aol.com

1 Ferriman A. WHO accused of stifling debate about infant feeding. BMJ 2000;320:1362. (20 May.)

\section{Experts' opinions seemed to be disregarded}

EDITOR-Ferriman in her news article writes about the World Health Organization's technical consultation on infant feeding, to which the WHO had invited 28 experts in the field, including myself.

At the start of the meeting, we found that two important background papers for the consultation exercise were missing from our folders. One of those was on the international code of marketing of breast milk substitutes by Ellen Sokol and the other was a paper on globalisation and infant feeding by Judith Richter. When some of us requested those documents, we were informed by the WHO staff that both papers were being revised. When we finally received those papers, the authors, who were both present, confirmed that both documents had been considerably edited.

The experts worked in several groups on different issues relating to the feeding of infants and young children. Independently, without any previous agreement between them, all the groups suggested the urgent need to state "about six months of age" as the best recommendation for the age of introduction of complementary foods to babies. The technical staff from the WHO, however, refused to allow any such discussion. We were not happy with this new development because there had been no mention of any restriction on the topics for discussion when we were initially invited to participate in the consultation.

It seems that the experts invited by the WHO specifically for this consultation were not in a position to give an opinion on this particular issue. What, then, was the need for experts if their expert opinion was going to be disregarded?

For many years the WHO's statements about feeding infants have recommended four to six months for exclusive breast feeding, but the World Health Assembly's resolution 47.5 of May 1994 clearly states that complementary food should be introduced at about six months of age. In fact, to start with complementary food at about six months is equivalent to endorsing exclusive breast feeding for about six months However, no WHO document explicitly makes this statement. Why does the WHO persist in this ambiguity?

Fernando Vallone head, breastfeeding subprogramme Mother and Child Programme, Ministry of Health, Buenos Aires Province, Argentina fvallone@intramed.net.ar

\section{Ferriman A. WHO accused of stifling debate about infant} feeding. BMJ 2000; 320:1362. (20 May.)

\section{Inconsistencies need to be resolved}

EDITOR-I want to add further comment to Ferriman's news article concerning the debate over the current recommendation of the World Health Organization regarding the duration of exclusive breast feeding. ${ }^{1}$ This recommendation has remained "four to six months" for over two decades. The need to review the more recent research and update this recommendation has been argued for several years. International agencies, governments of several nations, and respected professional organisations with concerns for the health of mothers, infants, and young children have carried out such reviews and concluded that the evidence is now sufficient to adjust the recommendation to "about six months." Even within the WHO there is inconsistency with some publications referring to the old recommendation and others indicating about six months. These inconsistencies are confusing and need resolution.

At the jointly sponsored meeting of the WHO/Unicef on feeding infants and young children held in Geneva in March 2000 technical consultants-invited to participate in this event because of recognised expertise on infant feeding-were advised before the meeting that the duration of exclusive breast feeding would not be on the agenda. The consultants found it impossible, however, to discuss improving the feeding of infants and young children without noting the need to 


\section{WHO Technical Consultants' statement on the duration of exclusive breast feeding}

\section{Submitted 17 March 2000, WHO Headquarters, Geneva}

At the time of the Innocenti meeting in 1990, the evidence regarding the importance of exclusive breast feeding during the first six months of life was limited, and the recommendation of promoting, protecting, and supporting exclusive breast feeding for four to six months was acceptable. During the intervening 10 years numerous further studies regarding the biologic importance of exclusive breast feeding, the development of the infant (neurologically, immunologically, metabolically, and in terms of oral motor development), as well as carefully done work clarifying the physiology of lactation and milk production have accumulated. Simultaneously, studies have been carried out that show the significant risks to infant health and to lactation, milk production, and lactational infertility of the premature introduction of complementary foods and replacements for breast feeding. There is now sufficient scientific (including epidemiological) evidence for changing the recommendation of exclusive breast feeding to about six months.

The technical consultants who have gathered here in Geneva to assist the WHO and Unicef in developing recommendations for the feeding of infants and young children believe that it is essential for the strategic plan for the first decade of the new millennium that will result from our work to reflect the current scientific evidence and refer to the recommended duration of exclusive breast feeding as about six months. Such guidance to those responsible for strategic planning at an international, national, and community level and programmatic action will appreciably improve the survival and the health and development of all of the world's infants and children.

Lubov Abolian (Russia), Marcos Arana (Mexico), Ruth Elena Arango (Guatemala), Kathryn Dewey (USA), Judith Galtry (New Zealand), Elsa Giugliani (Brazil), Gülbin Gökçay (Turkey), Rukhsana Haider (Bangladesh), Xu Jingzhen (China), Sandra Lang (United Kingdom), Katherine Krasovec (USA), Alireza Marandi (Islamic Republic of Iran), Kim Fleisher Michealsen (Denmark), Audrey Naylor (USA), Chloe O'Gara (USA), Marina Ferreira Rea (Brazil), Judith Richter (Germany), Ellen Sokol (USA), Veronica Valdes (Chile), Fernando Vallone (Argentina)

update the recommendation on exclusive breast feeding. When it became clear that recommendations regarding this matter were not acceptable to the organisers, a statement, noting the need to update the recommendation in light of more recent scientific evidence, was prepared by 20 of the 28 consultants who were not WHO/Unicef staff and read into the record during the final plenary session (box).

The consultants were concerned not only about the specific issue of infant feeding but also about the restriction on discussion or debate of the matter. In an era when terms such as "evidence based," "transparent," "democratic and open discussion" are commonly used when describing the decision making process, such restriction resulted in both discontent and disappointment. The WHO has always been a trusted leader in providing scientifically sound technical guidance on matters related to improving global health. Restriction of debate seriously weakens this trust.

Audrey J Naylor president

Wellstart International, San Diego, CA 92103, USA

1 Ferriman A. WHO accused of stifling debate about infant feeding. BMJ 2000;320:1362. (20 May.)

\section{All commercial enterprises should be excluded from the development process}

EDITOR-Ferriman in her news article raises the possibility that the World Health Organization's recommendations on infant feeding are influenced by the baby food industry. ${ }^{1}$ Close interactions with pharmaceutical companies have already tarnished the credibility of the WHO. The guidelines on the management of hypertension, sponsored by the WHO, have been found to contain several flaws. ${ }^{23}$ One recommendation is a target reduction in blood pressure that is slightly lower than generally accepted. Another recommendation is in disagreement with authoritative sources. ${ }^{4-6}$

The consequences of following these guidelines could be unnecessary drug treatment, overmedication, and an increased potential for adverse reactions. Obvious beneficiaries are pharmaceutical companies, which market antihypertensive drugs. Since the press release of the guidelines was sponsored by Astra, which stands to profit from their use, it is easy to conclude that the experts may have had competing interests. After much criticism, the WHO has stated that it will review the hypertension guidelines, but they are still being distributed.

The WHO seems to be convinced that partnerships with commercial enterprises are beneficial and overlooks the inherent competing interests between public health and commercial goals. We do not see how any sort of company involvement in the development of guidelines is in the interest of public health. Accepting donations from companies compromises the WHO and could jeopardise the value of the advice and image of the organisation. It would be naive not to recognise that the donor company will be expecting a quid pro quo, such as financial gain or being seen as one of the "good guys". The only way to ensure the credibility of any recommendations sponsored by the $\mathrm{WHO}$ is to exclude all commercial enterprises from the development process.
The WHO should not permit commercial enterprises of any sort directly to fund publications as the information may be regarded as compromised. Prescribers are likely to disregard such information if it is distributed by a pharmaceutical company. It is essential that the WHO retains its editorial and publishing autonomy and remains independent of company involvement.

Christophe Kopp president, International Society of Drug Bulletins

la revue Prescrire, 75527 Paris Cedex, France

Andrea Tarr treasurer, International Society of Drug Bulletins

Drug and Therapeutics Bulletin, London NW1 4DF

1 Ferriman A. WHO accused of stifling debate about infant feeding. BMJ 2000; 320:1362. (20 May.)

2 World Health Organization-International Society of Hypertension Guidelines Subcommittee 1999 World Health Organisation-International Society of HyperHealth Organisation-International Society of Hyper-

tension Guidelines for the
J Hypertens 1999;17:151-83.

Prescrire Editorial Staff. Flawed WHO recommendations on hypertension. Prescr Int 1999;8:121-3.

4 Ramsay L, Williams B, Johnston G, MacGregor C, Poston L, Potter J, et al. Guidelines for management of hypertension: report of the third working party of the British Hypertension Society. J Hum Hypertens 1999;13: $569-92$

5 National Institutes of Health. The sixth report of the Joint National Committee on prevention, detection, evaluation, and treatment of high blood pressure. Bethesda: NIH, 1997:1-70.

6 Association Médicale Canadienne. Recommendations de 1999 pour le traitement de l'hypertension artérielle au Canada. Can Med Assoc J 1999;161: SF 1-25.

\section{World Health Organization's response}

EDITOR-Throughout the world, officials and legislators responsible for devising and implementing health policies look to the WHO for authoritative guidance on complex issues that relate to people's health. Malnutrition-particularly of infants and young children-leads to serious consequences, including disability and death, especially in the world's poorest communities. The 191 member states of the WHO have often debated nutrition issues and have requested the organisation to formulate and secure agreement for a strategy on infant and young child feeding that reflects the best available evidence on ways to reduce rates of child malnutrition.

To help establish a framework for this strategy, the WHO and Unicef invited a carefully selected group of people, experienced in the implementation of strategies for improving child nutrition, to a consultation meeting in March 2000. The consultation's terms of reference included identifying critical issues for discussion between the WHO, its member states, and other interested parties as the strategy is developed.

The optimal duration of exclusive breast feeding in different settings throughout the world is intensely debated. Groups concerned with public health policy, breast feeding advocates, and commercial entities that manufacture and distribute both breast milk substitutes and complementary foods are all active participants. The member states of the WHO have requested an authoritative examination of this issue, and the organisation is undertaking a systematic review of the scientific evidence in accordance with the Cochrane Collaboration's criteria and framework. The review's findings, 
including implications for the WHO's current infant feeding recommendations, ${ }^{1}$ will be the subject of more substantive examinations in 2001.

The WHO seeks to facilitate informed debate in ways that best respond to the interests of its member states and their citizens. This may not always reflect the interests of individuals and organisations that are keen for the WHO to be associated with a specific recommendation in public health policy and are impatient with the structured process of scientific analysis that the organisation is expected to pursue.

Because this research is under way, both the consultation's terms of reference and the selection of participants precluded in depth discussion of the optimal duration of exclusive breast feeding.

The authors of papers for the technical consultation in March 2000 signed the standard agreement with the WHO. This specifies that, once written, a paper is WHO property. Generally, papers are edited for length, focus, and relevance to the meeting's objectives, and in terms of evidence presented, so that they reflect the standards of scientific objectivity and balance that are required of the organisation by its member states. Particular attention is paid to the quality of evidence that is presented if named WHO member states, public bodies, or commercial entities are subject to criticism. When possible, editing is undertaken in consultation with authors; in this instance, many of the changes that the WHO had requested for two of the papers had not been sufficiently reflected in the authors' modified versions.

The views expressed by Kopp et al have been thoroughly discussed within the WHO. The guidelines were originally prepared in 1997-8. In 1999 the director-general decided that the guidelines should be reviewed in collaboration with the International Society for Hypertension in the light of the most up to date evidence. They should also take into consideration public health implications of the key recommendations. Accordingly, a new method for the development of guidelines was prepared and discussed by a multidisciplinary group of experts, including representatives of the society, in a meeting held in Geneva in July. This method is now being applied to update the hypertension guidelines. In the new guidelines, recommendations will be graded according to the level of supporting evidence and attention will be given to the cost effectiveness of interventions. The draft guidelines will be circulated for review by a wide circle of experts before they are officially endorsed. Meanwhile, the WHO has added a reference to the review process to its web page (www.who.int/nut/).

David Nabarro executive director Office of the Director-General, World Health Organization, CH-1211 Geneva, Switzerland

1 The World Health Organization's infant-feeding recommendation. Wkly Epidemiol Rec 1995;70:119-20.

\section{Nestlés violation of international marketing code}

\section{The auditors respond}

EDITOR-Yamey did not give an accurate summary of the findings of our audit of Nestle's infant food marketing practices in Pakistan. ${ }^{1}$ It should be clarified that we did not investigate the allegations made by Syed Aamar Raza. What we undertook was an audit of policies, procedures, and operational systems, cross checked by internal and external surveys. Whereas we concluded that Nestlé Milkpak's operations are in compliance with the letter and spirit of the World Health Organization's code of marketing of breast milk substitutes, Yamey focused on the violations of the code that we did find, implying that our conclusion is not justified by the facts.

We found that Nestlé Milkpak had in place a consistent framework of policies, procedures, and work instructions to ensure compliance with the code, that the code is embedded in the culture of the company, and that Nestlé tried to mitigate pressure from the marketplace that may have led to code violations.

Yamey did not discuss the nature of the three instances of violation identified in our audit. The gifts offered to health professionals amounted to a jar of instant coffee and some non-medical books. The failure to disclose financial assistance to health professionals was actually a failure to disclose such assistance to the heads of their institutions. The bonuses that were provided to sales staff were from one distributor that had failed to separate infant formula products from other products when calculating staff bonuses and whose sales account for less than 2\% of Nestlé Milkpak's total infant formula sales.

In the article Anna Taylor, an adviser to Save the Children, stated that the audit suggests that Nestlé uses health system facilities to promote its products. What she is referring to is the practice of medical detailing, by which Nestlé medical delegates inform doctors of the properties of Nestlé products. This is scientific information that conforms fully to the relevant articles (4.2 and 7.2) of the code.

The marketing of breast milk substitutes is an important issue; a serious study of the marketing practices of a company such as Nestlé Milkpak deserves accurate reporting.

Sunil Sinha director

Emerging Market Economics, London E14 9XP sinhas@emergingmarkets.co.uk 1 Yamey G. Nestlé violates international marketing code,
says audit. BMJ 2000;321:8. (1 July.)

\section{Nestlé responds}

EDITOR-Yamey totally misrepresented the findings of the independent audit. ${ }^{1}$ The executive summary of the audit report, written by the respected international auditors Emerging Market Economics (EME) and which can be read on our website, stated: "it is clear that the WHO code and the Nestlé instructions are embedded in the policies, procedures, structures, and resource allocation of all the company's functions and work processes." The audit found three instances of violation of the WHO code, but the auditors stated that "these violations appear to be of the letter rather then the spirit of the code."'

Part of Nestlés commitment to the code is to thoroughly investigate alleged violations and make changes if necessary. The three breaches, one of which was a gift to a doctor of a jar of coffee and some non-medical books, have been corrected. Yamey's article on the alleged violations does not reflect the generally positive tone of the report of the external auditors, especially in the light of the scope and nature of the allegations made against the company.

The photograph accompanying the article is unclear, and it is understandable that Yamey qualifies its use by saying that it "allegedly shows mothers in Pakistan carrying free Nestlé samples." If the mothers do have Nestlé samples, these will be of Cerelac, a complementary food product, which is not marketed as a breast milk substitute and is thus not covered by the code. As Emerging Market Economics reported, the audit found no evidence of inappropriate gifts to mothers.

David Hudson communications and corporate affairs director

Nestlé UK, Croydon CR9 1NR

d.hudson@nestlegb.nestle.com

1 Yamey G. Nestlé violates international marketing code, says audit. $B M J$ 2000;321:8. (1 July)

2 www.babymilk.nestle.com (accessed 15 Sep 2000).

\section{Audit report fudges the issue}

EDITOR-The external audit report on Nestlés infant food marketing practices in Pakistan, as discussed by Yamey, is a whitewash. ${ }^{1}$ The report was undoubtedly commissioned in response to former employee Syed Aamar Raza's allegation that Nestlé had violated the international marketing code. How could the auditors possibly have ignored the damning evidence that Raza put in the public domain? I have analysed Raza's evidence and question how any independent audit could manage not to find anything that would either corroborate or refute the existence of the practices he highlighted.

The audit uses the international code of marketing of breast milk substitutes (inaccurately referred to as the World Health Organization's code) and the Nestlé instructions as the benchmarks to measure compliance. The instructions differ sharply from the code-were the auditors not aware of these differences? And were they not aware of subsequent World Health Assembly resolutions that clarify the code? Did they know that these subsequent resolutions enjoy the same status as the code? As the audit was commissioned by Nestlé, how much was it circumscribed by perimeters set by Nestlé?

A statement in the report claims that the Nestlé instructions were developed in consultation with the WHO. Neither the WHO nor 
Unicef has ever endorsed or refuted any company's interpretation of the code.

In an analysis comparing the Nestlé instructions and the code, I found Nestlés interpretation to be incompatible with the letter and spirit of the code and subsequent World Health Assembly resolutions in many ways. (The analysis is available from me.) If the Nestlé instructions were the guiding instrument in auditing the activities of Nestlé in Pakistan, then perhaps the auditors were right in finding only three instances of violation. But the auditors' conclusion that Nestlé is in compliance with the letter and spirit of the code is inexplicable.

I take issue with the auditors' statement that poor awareness of the code among health professionals has resulted in an uneven playing field in Pakistan. The auditors are shifting the burden of compliance to third parties, whereas the buck should stop with the company itself. The auditors' recommendation that health professionals should undertake courses on the code (with the explicit understanding that training would be funded by Nestlé) is equally untenable. Instead the auditors should have recommended that Nestlé train its staff in the code, not in its flawed instructions, and that they should do it well. Good training, however, would entail Nestlé teaching its staff not to put profit before the wellbeing of young children in Pakistan.

Yeong Joo Kean legal adviser

International Code Documentation Centre,

PO Box 19, 10700 Penang, Malaysia

ibfanpg@tm.net.my

1 Yamey G. Nestlé violates international marketing code, says audit. $B M J$ 2000;321:8. (1 July.)

\section{Similar practices take place in Europe}

EDITOR-Yamey reported Nestlés violation in Pakistan of the World Health Organization's international code of marketing of breast milk substitutes. ${ }^{1}$ We should look at what happens in Europe, too. In a survey on the financing of continuing medical education of paediatricians in the Naples area, I interviewed 136 paediatricians $(17 \%$ of the total) concerning the support they received from the baby food industry to attend national and international meetings during 1998 (table). One hundred and twenty (88\%) reported that their travel or hotel expenses, or both, had been paid fully by the industry; 60 paediatricians had received medical or computer equipment for their office.

Support by baby food companies of continuing education of paediatricians in the Naples area

\begin{tabular}{lc} 
Sponsor & \% of total \\
\hline Not specified & 25 \\
\hline Nestlé & 23 \\
\hline Milupa & 13 \\
\hline Humana & 12 \\
\hline Plasmon & 7 \\
\hline Abbott & 5 \\
\hline $\begin{array}{l}\text { Nutricia, Guigoz, Dicofarm, Dieterba, } \\
\text { and Mellin }\end{array}$ & 3 \\
\hline Total & 88 \\
\hline
\end{tabular}

The main baby food companies were recently condemned by the Italian Competition Authority because of their refusal to sell their products through the usual market: in Italy, infant formula is at present sold only in pharmacies and at a much higher cost than in most European countries. ${ }^{2}$ Moreover, the authority reports cases in several Italian hospitals of gifts of formula milk and medical equipment to maternity wards. The authority notes that it is not surprising that when a neonate goes home a formula milk is prescribed, even if the mother is breast feeding. (The words "if breast milk should not be enough" are usually written on the discharge card.) The type of formula that is prescribed changes every 2-3 months, as do the discharge cards, which are printed and distributed by the baby food companies.

The baby food companies have nevertheless found a way of complying with the WHO code. Furthermore, they have a strong influence on paediatricians, who usually prescribe a formula during transitional lactational crises-the most frequent reason for interruption of breast feeding during the baby's first three months."

Alfredo Pisacane senior lecturer

Department of Paediatrics, University of Naples, Naples 80131, Italy

pisacane@unina.it

1 Yamey G. Nestlé violates international marketing code, says audit. $B M J$ 2000;321:8. (1 July.)

2 Italian Competition Authority, www.agcm.it (accessed 15 Sep 2000).

3 Dipartimento di Pediatria di Napoli. Indagine

sull'allattamento materno in Campania e in Umbria. Naples: sull'allattamento materno in Campania e in
Dipartimento di Pediatria di Napoli, 1995.

\section{Unicef and baby food manufacturers}

\section{Unicef continues to base its actions and programmes on the best interests of the child}

EDIToR-I write with reference to Yamey's article about the alliances Unicef is seeking to form with manufacturers of infant formula that do not comply with the international code of marketing of breast milk substitutes. ${ }^{1}$ Unicef does not accept donations from manufacturers of infant formula whose marketing practices violate this code and subsequent World Health Assembly resolutions Unicef stands firmly behind the code and will continue its longstanding support for breastfeeding programmes worldwide.

Over the past few months there has been considerable discussion within Unicef about our relationships with the corporate community, including manufacturers of infant formula milk. This internal discussion emerged mainly because Unicef is one of the cosponsoring agencies of UNAIDS and has, at the request of the United Nations secretary general, participated in discussions with five large pharmaceutical companies on the possibility of obtaining various drugs to fight HIV/AIDS at discounted prices on behalf of developing countries. One of these companies is widely viewed as violating the code.
Some people inside and outside Unicef have misinterpreted our participation in these discussions as a sign that we are weakening our support for breast feeding and the code. Nothing could be further from the truth. Unicef believes that in the face of AIDS our support for breastfeeding must be strengthened, not diminished.

Nonetheless, when we think that a company-any company-may offer a compelling solution to a crucial child health problem such as HIV/AIDS, we will explore how to get that company working on behalf of children and women. At the same time, Unicef will uphold its support of the code and will continue to call violators of the code to account publicly.

Are the issues complex? Yes. Is the growing calamity of HIV/AIDS forcing us all to consider new approaches to our work? Absolutely. That's why the debate in Unicef is spirited. But regardless of our soul searching on how best to navigate through the sometimes conflicting policy issues raised in part by AIDS, Unicef remains resolutely committed to breast feeding and the many benefits it provides to both mother and child. At the same time, Unicef recognises that mothers infected with HIV face an agonising dilemma on how best to feed their infants and strongly supports the efforts of researchers better to understand this crucial area of transmission.

Finally, as has been the case throughout the 10 years since the ratification of the convention on the rights of the child, Unicef will strive to base its actions and programmes on the best interests of the child.

Carol Bellamy executive director

Unicef, Unicef House, 3 United Nations Plaza, New York, NY 10017, USA

Media@UNICEF.org

1 Yamey G. Unicef accused of forming alliance with baby food industry. BMJ 2000;321:132. (14 July)

\section{Compliance to the code is difficult to judge}

EDITOR-Yamey's article raises important issues about the partnerships between the United Nations, non-governmental organisations, and industry. ${ }^{1}$

We appreciate the courage that Unicef, more than any other UN agency, has shown over the past two decades in speaking out about corporate practices that undermine infant health. A key factor has been Unicef's understanding of the influence that inappropriate sponsorship and partnerships can have. Carol Bellamy, the executive director of Unicef, has confirmed that Unicef will continue to refuse donations from manufacturers of infant formula that violate the international code of marketing of breast milk substitutes and subsequent World Health Assembly resolutions, but we do have other concerns-for example, the following. - What about manufacturers of other breast milk substitutes, bottles, teats, or the new "medical" foods-all products that are promoted in ways that undermine breast feeding? 
- Are partnerships with corporations really the best way to find appropriate solutions to HIV/AIDS? Surely the world health community can research this problem without having to beg from companies who will inevitably look for wealth generating answers? There will never be a commercial incentive to research exclusive breast feeding, yet recent research has shown that it may prove to be a more appropriate way to combat HIV transmission

- How will Unicef judge compliance of a partner or other company to the code? Even in the face of the most compelling evidence, companies will argue their innocence. ${ }^{2}$ Rightly or wrongly, the public expects the UN to provide an independent and authoritative view

- How will Unicef protect its right to speak out? In January this year at the executive board meeting of the World Health Organization the intervention of the International Baby Food Action Networks included a comment exposing a report by a baby food company which claimed that it followed the code. Unicef and other agencies had been outspoken in their criticism of the report, and Unicef had given permission for its critique to be made public. The WHO, which is actively pursuing partnerships with industry, pressured us to remove this section completely. ${ }^{3}$ We refused and said that, rather than edit it, we would hand it to members of the executive board and the media. In the event the entire speech was delivered as drafted. But the critical piece about the company was deleted from the provisional summary record.

If we are to have informed debates about issues that affect public health so profoundly, surely all of us working in the interests of public health should be encouraged to express our concerns frankly.

Patti Rundall policy director

Baby Milk Action, Cambridge CB2 3AX

prundall@babymilkaction.org

Nancy-Jo Peck scientific adviser

International Baby Food Action Network-Geneva

Infant Feeding Association, PO Box 157,

1211 Geneva 19, Switzerland

philipec@iprolink.ch

1 Yamey G. Unicef accused of forming alliance with baby food industry. BMJ 2000;321:132. (14 July.)

2 Yamey G. Nestlé violates international marketing code says audit. BMJ 2000;321:8. (1 July.)

3 Ferriman A. WHO accused of stifling debate about infant feeding. BMJ 2000;320:1362. (20 May.)

\section{Comparing health inequality in men and women}

\section{Choice of indicator is important}

EDITOR-The paper by Sacker et al, ${ }^{1}$ and the associated editorial by Vågerö, ${ }^{2}$ discuss differences in health inequality between men and women measured with two alternative schemes. We have been investigating a similar problem-the indicators that are most sensitive for measuring health inequalities in an older population.

Sacker et al included only those people in paid work in 1981. The 1981 census shows that $20 \%$ of men and $49 \%$ of women in the age groups they consider were not working, so this restriction will have resulted in many people in the sample being excluded. Such exclusions are known to result in bias. ${ }^{3}$ In the older population the use of classifications based on current occupation is problematic. Other common indicators of socioeconomic status, such as income and education, also present difficulties. This is because of the strong association between income and employment status and because most of today's older population (particularly women) left school at the minimum age with no academic qualifications.

The data we use come from a nationally representative sample of 55-69 year olds first surveyed in 1988. ${ }^{4}$ The dataset includes lifetime occupational histories, which have allowed us to compute a social class measure based on usual occupation and exclude only $4 \%$ of men and $9 \%$ of women. Information on qualifications (including those obtained through on the job training), income, and two indices of relative deprivation is also available.

The table shows the proportions of men and women reporting "not good" or "fair" (rather than good) health by these indicators. Differentials among men and women using the measure of social class were broadly similar, as were differentials by quarter of income and education. In both sexes the Townsend score produced the greatest differentiation; over three fifths of the sample, however, fell into the most advantaged category. It might be valuable if the score was used in conjunction with an indicator such as education, which, in older groups, has the opposite problem-that is, lack of differentiation at the bottom of the distribution.

Choice of an indicator will depend on theoretical models of relations between socioeconomic factors and particular health outcomes as well as on apparent sensitivity. The principle of inclusiveness is also extremely important and can be met in some circumstances by the collection of retrospective data.

Gemma Holt research assistant Gemma.Holt@lshtm.ac.uk

Emily Grundy reader

Centre for Population Studies, London School of Hygiene and Tropical Medicine, London WC1B 3DP

1 Sacker A, Firth D, Fitzpatrick R, Lynch K, Bartley M. Comparing health inequality in men and women: prospective study of mortality 1986-96. BMJ 2000;320 1303-7. (13 May.)

2 Vågerö D. Health inequalities in women and men. $B M J$ 2000;320:1286-7. (13 May.)

3 Martikainen P, Valkonen T. Bias related to the exclusion of the economically inactive in studies on social clas differences in mortality. Int J Epidemiol 1999;28:899-904.

4 Disney RE, Grundy E, Johnson P, eds. The dynamics of retirement: analyses of the retirement surveys. London: Department of Social Security Research, 1997. (Report No 72.)

5 Townsend P. Poverty in the United Kingdom: a survey of household resources and standards of living. Middlesex: Penguin, 1979

Risk of "not good" or "fair" health (age adjusted odds ratios and 95\% confidence intervals) by socioeconomic indicators among men and women aged 55-69, Great Britain (England, Wales, and Scotland), 1988-9

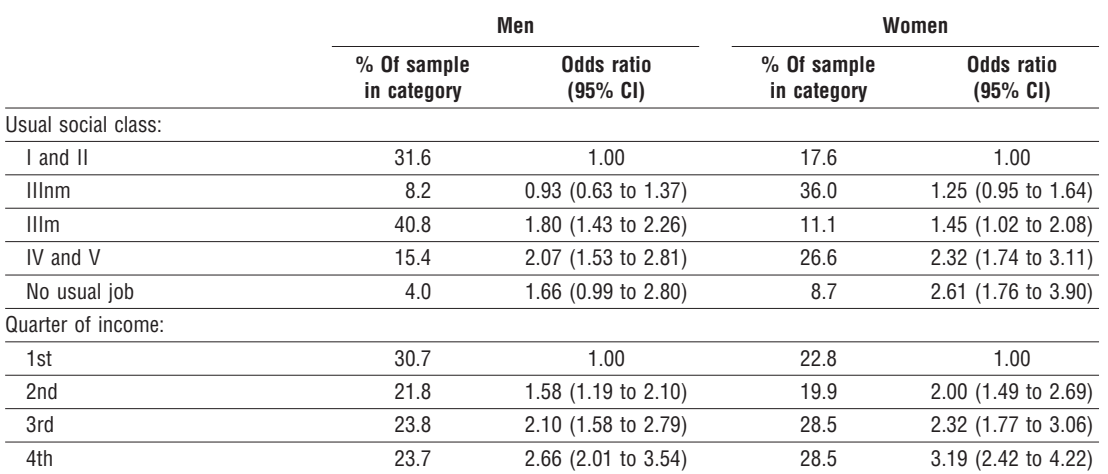

Educational level:

\begin{tabular}{llcrc}
\hline A Level or equivalent or higher & 14.4 & 1.00 & 8.6 & 1.00 \\
\hline 0 Level or equivalent & 10.4 & $0.84(0.55$ to 1.27$)$ & 10.7 & 1.17 (0.76 to 1.81) \\
\hline Trade or commercial & 23.0 & $1.86(1.34$ to 2.60$)$ & 13.9 & $1.43(0.96$ to 2.16$)$ \\
\hline None & 52.2 & $2.23(1.65$ to 3.00$)$ & 66.8 & 2.36 (1.67 to 3.34) \\
\hline Durables (No that respondents were unable to afford)* & & &
\end{tabular}

Durables (No that respondents were unable to afford) *:

\begin{tabular}{lrccc}
\hline 0 & 68.4 & 1.00 & 60.5 & 1.00 \\
\hline 1 & 11.4 & $1.65(1.21$ to 2.26$)$ & 14.6 & 1.74 (1.33 to 2.29) \\
\hline 2 & 8.3 & $2.10(1.46$ to 3.05$)$ & 10.0 & 2.11 (1.53 to 2.92) \\
\hline$\geqslant 3$ & 11.9 & $3.70(2.66$ to 5.23$)$ & 14.6 & 2.57 (1.94 to 3.44) \\
\hline Townsend deprivation indicatorst: & & & & \\
\hline 0 & 69.5 & 1.00 & 63.2 & 1.00 \\
\hline 1 & 17.1 & $1.48(1.13$ to 1.92$)$ & 19.6 & 1.52 (1.19 to 1.93$)$ \\
\hline 2 & 5.0 & $4.30(2.61$ to 7.38$)$ & 7.0 & 1.70 (1.17 to 2.48) \\
\hline$\geqslant 3$ & 8.4 & $8.33(5.21$ to 14.01$)$ & 10.2 & 4.47 (3.10 to 6.59$)$ \\
\hline
\end{tabular}

*Items that respondents reported lacking because they could not afford them: colour television; refrigerator; fridge-freezer washing machine; tumble dryer; telephone; dishwasher; video; central heating; use of car.

†ltems that respondents reported lacking because they could not afford them: cooked meal every day; meat or fish every other day; roast meat once a week; winter coat; two pairs of shoes; new clothes when needed; presents for friends; celebrations; holiday away from home; holiday abroad every year or so. Based on Townsend's poverty measures. ${ }^{5}$ 


\section{Authors' reply}

EDiton-We are pleased to see that other researchers are also measuring different dimensions of inequality. It is important to know about their varying effects on health and whether effects are different at different stages of life.

In our paper we asked why it might be that health inequality seems greater in men than women in some studies, though not in others. One reason that has been put forward is that studies use different measures of inequality. This was particularly interesting to us, as the wider programme of work from which our paper emerged investigated the possibility that different forms of inequality could influence health through different pathways. These suspicions were borne out, and the results are published elsewhere. $^{12}$

Our aim was limited to a single hypothesis. We did not aim to locate the most inclusive measure of social inequality, although we agree that such an aim is indeed an important one in other studies and for other research questions. We suspected that social class based on occupational relations and conditions would not be as powerfully related to health in women as in men of working age. The strongest test of this could be carried out with women who had an occupation at the time of the census. It would have been superfluous to look at past occupation because this would have been most unlikely to change the answer to this particular research question.

The Office for National Statistics' longitudinal study is based on the census and does not include measures of past occupation. A more serious problem for some purposes is that the longitudinal study does not contain data on income, education, access to consumer durables, or health related behaviours. The dataset used by Holt and Grundy is far richer. It enables them to ask such questions as, Is income related to health independent of education (which other studies show both increases earning potential and improves health behaviours)? Unfortunately, at present there are no datasets that include all these items of information and are linked to mortality.

Amanda Sacker senior research fellow

Mel Bartley principal research fellow

Department of Epidemiology and Public Health, University College London, London WC1E 6BT

David Firth senior fellow in statistics for the social

sciences

Nuffield College, Oxford University, Oxford

OX1 1NF

Ray Fitzpatrick professor of public health and primary care

Institute of Health Sciences, Oxford University, Oxford OX3 7LF

1 Bartley M, Sacker A, Firth D, Fitzpatrick R. Understanding social variation in cardiovascular risk factors in women and men: the advantage of theoretically based measures. Soc Sci Med 1999;49:831-45.

2 Sacker A, Bartley M, Firth D, Fitzpatrick R. Social inequalities in the health of women in England: occupational, material and behavioural pathwavs. Soc Sci Med (in press). 3 Lynch JW, Kaplan GA, Cohen RD, Tuomilehto J, Salonen JT. Do cardiovascular risk-factors explain the ratation J1. Do cardiovascular risk-factors explain the relation between socio-economic status, risk of all-cause mortality, Am J Epidemiol 1996;144:934-42.

\section{Towards explaining health inequalities}

EDITOR-Vågerö's editorial has opened up an issue that our paper on health inequality in men and women did not discuss in any detail. ${ }^{2}$ Research into health inequality now aims to move away from description and towards explanation. This means that measures of socioeconomic position need to be chosen with reference to hypotheses about how health inequalities are produced. In previous research on health inequality in women, inconsistency of results has forced us to question the assumption that the causes of health inequality are the same in men and women. This forces us to pay more attention to the appropriateness of our measures for our theories of how social structure acts on health.

We have carried out an explicit test of what researchers have in fact been implicitly thinking when they relate the health of married or cohabiting women to the occupational social class of their partners, as advocated by Vågerö. There is something about either the material or the cultural advantage or disadvantage of household circumstances that affects women's health more strongly than their own occupation. Also implicit is the assumption that there is a stronger correlation between the male (than the female) partner's occupationally defined social class and the general social and material advantage and lifestyle of the household. Given this hypothesis about the source of health inequalities in women, and the existence of an independent measure of household advantage, to rely on the husband's occupational class as a proxy for household advantage would not have been appropriate.

As the National Statistics' socioeconomic classification comes into use in British vital and official statistics and the 2001 census (including the next occupational mortality supplement), these issues will no doubt be debated at far greater length. We are pleased that Vågerö's editorial has opened up this discussion in such a timely fashion.

Mel Bartley principal research fellow mel@public-health.ucl.ac.uk

Amanda Sacker senior research fellow Department of Epidemiology and Public Health, Royal Free and University College London, London WC1E 6BT

David Firth senior fellow in statistics for the social sciences

Nuffield College, Oxford OX1 1NF

Ray Fitzpatrick professor of public health and primary care

Institute of Health Sciences, University of Oxford, Oxford OX3 7L

Kevin Lynch computing research officer

Centre for Longitudinal Studies, Institute of

Education, London WC1H 0AL

1 Vågerö D. Health inequalities in women and men. $B M /$ 2000;320:1286-7.(13 May.)

2 Sacker A, Firth D, Fitzpatrick R, Lynch K, Bartley M. Comparing health inequality in men and women: prospective study of mortality 1986-96. $B M J$ 2000;320: prospective study of mortality 1986-96. BMJ 2000;320: 1303-7. (13 Mav.)

\section{Sterilise in haste, repent at leisure and great expense}

EDITOR-Roberts's editorial on good practice in sterilisation well summarises the technical issues involved in surgical sterilisation but passes lightly over the social, psychological, and ethical issues attached to this highly personal topic. ${ }^{1}$ I do not know if the Royal College of Obstetricians and Gynaecologists' publication-the main source for the editorial-does any better, but I wish to discuss here a point that has been raised in the literature on assisted conception.

A considerable proportion (over 10\%) of requests for fertility treatment now come from men and women who underwent surgical sterilisation to please a previous partner and have subsequently remarried (including, ironically, the first successful case of in vitro fertilisation). ${ }^{3}$ Such treatment is expensive and traumatic and usually fails, in the case of vasectomy because of high titres of antisperm antibodies and the low success rate of intracytoplasmic sperm injection and in vitro fertilisation generally.

The only counselling that is given before sterilisation in most clinics is the information that the operation will be difficult to reverse. There may be no request to interview the partner or to discuss the matter further. An andrologist I know, who makes his living performing surgical reversals and difficult sperm recovery procedures, tells me that demand for sterilisation of the partner is often a symptom of rejection, which is followed quite soon by departure of the spouse. I am acquainted with several people to whom this has happened.

In cases in which the demand comes from the partner who is not the subject of the operation, informed consent is a misnomer but rather resembles taking a cat to the vet. The cost of failed in vitro fertilisation procedures in this country is about $£ 100 \mathrm{~m}$ annually; most of these procedures are paid for privately and of course keep the cash registers of the in vitro fertilisation industry ringing merrily. Of that $£ 100 \mathrm{~m}$, at least $£ 10 \mathrm{~m}$ must relate to earlier surgical sterilisation procedures. Clearly this could be avoided if semen was stored before vasectomy ${ }^{3}$ or couples are urged through proper counselling to really think through the implications of mutilating the future fertility chances of either partner.

Edward Tuddenham professor of haemostasis Imperial College School of Medicine, Hammersmith Hospital, London W12 0NN edward.tuddenham@csc.mrc.ac.uk

1 Roberts H. Good practice in sterilisation. BMJ 2000;320: 662-3. (11 March)

2 Royal College of Obstetricians and Gynaecologists. Male and female sterilisation. London: RCOG, 1999.

3 Jequier AM. Vasectomy related infertility: a major and costly medical problem. Hum Reprod 1998;13:1757-9

4 Human Fertilisation and Embryology Authority. www. hfea.gov.uk 


\section{Breast feeding is a major factor in HIV transmission}

EDITOR-We disagree with Latham and Preble's statement that HIV transmission through breast feeding is rare and has been exaggerated. ${ }^{1}$ Worldwide about 600000 children a year are infected through mother to child transmission, mostly in subSaharan Africa, and breast feeding accounts for over a third of this number. ${ }^{2}$ At least 200000 infections worldwide cannot be dismissed.

In underresourced areas, such as most of sub-Saharan Africa, formula feeding will rarely be appropriate for most infants, whether or not they are exposed to HIV infection. ${ }^{2}$ However, like Zwi and Söderlund ${ }^{3}$ we conclude that the available data do not support a policy of excluding all feeding supplements used with breast feeding and of promoting exclusive breast feeding.

Latham and Preble's conclusions that "all the evidence suggests that mixed breast and formula feeding is the most dangerous feeding option" and that "exclusive breast feeding reduces HIV transmission" are premature. They base these conclusions on one observational study whose results are open to interpretation. ${ }^{2-4}$ Although it has health advantages for both babies and mothers and may render the infant's gut less permeable to HIV, ${ }^{12}$ exclusive breast feeding is uncommon in many countries (figure)..$^{5}$ The rate of exclusive breast feeding in subSaharan African countries is often less than $10 \%$ and exceeds $50 \%$ in only in a few countries. ${ }^{2}$ Further research is essential.

Breast feeding contributes substantially to the rate of transmission of HIV from mother to child, but until there are feasible alternatives it will remain the main method of feeding among both infected and uninfected women in poorer areas. ${ }^{2}$ We do not know whether exclusive breast feeding will reduce the risk of HIV transmissionbut even where breast feeding is universal, short courses of antiretroviral treatment in both mother and neonate reduce transmission from mother to child. Such treatment could have a major impact on the number of infected children worldwide.

Angus Nicoll consultant epidemiologist

PHLS Communicable Disease Surveillance Centre, London NW9 5EQ anicoll@phls.nhs.uk

Marie-Louise Newell reader

Catherine S Peckham professor

Department of Epidemiology and Biostatistics,

Institute of Child Health, University College

London, London WC1N 1EH

1 Latham MC, Preble EA. Appropriate feeding methods for Latham MC, Preble EA. Appropriate feeding methods for infants of HIV infected mother

BMJ 2000; 320:1656-9. (17 June.)
Nicoll A, Newell M-L, Peckham C, Luo C, Savage F. Infant 2 Nicoll A, Newell M-L, Peckham C, Luo C, Savage F. Infant
feeding and HIV-1 infection-year 2000. AIDS (in press). 3 Zwi K, Söderlund N. Commentary: The feeding debate is still unresolved and of secondary importance. BMJ 2000 320:1659-60.

4 Newell M-L. Infant feeding and HIV-1 transmission. Lancet 1999;354:442-3.

5 Haggerty P, Rutstein S. Breastfeeding and complementary infant feeding and the postpartum effects of breastfeeding. Calverton, MD: Demographic and Health Surveys, 1999. (DHS comparative studies No 30.)

\section{HIV/AIDS programmes should focus on improved access}

Editor-GlaxoWellcome's recent move to reduce the cost of antiretroviral drugs in sub-Saharan Africa, ${ }^{1}$ although to be applauded, is unlikely to have an impact on most of those infected with or affected by HIV/AIDS in sub-Saharan Africa. The cost of monitoring and treating patients with AIDS with antiretrovirals is high; even an antenatal screening programme creates

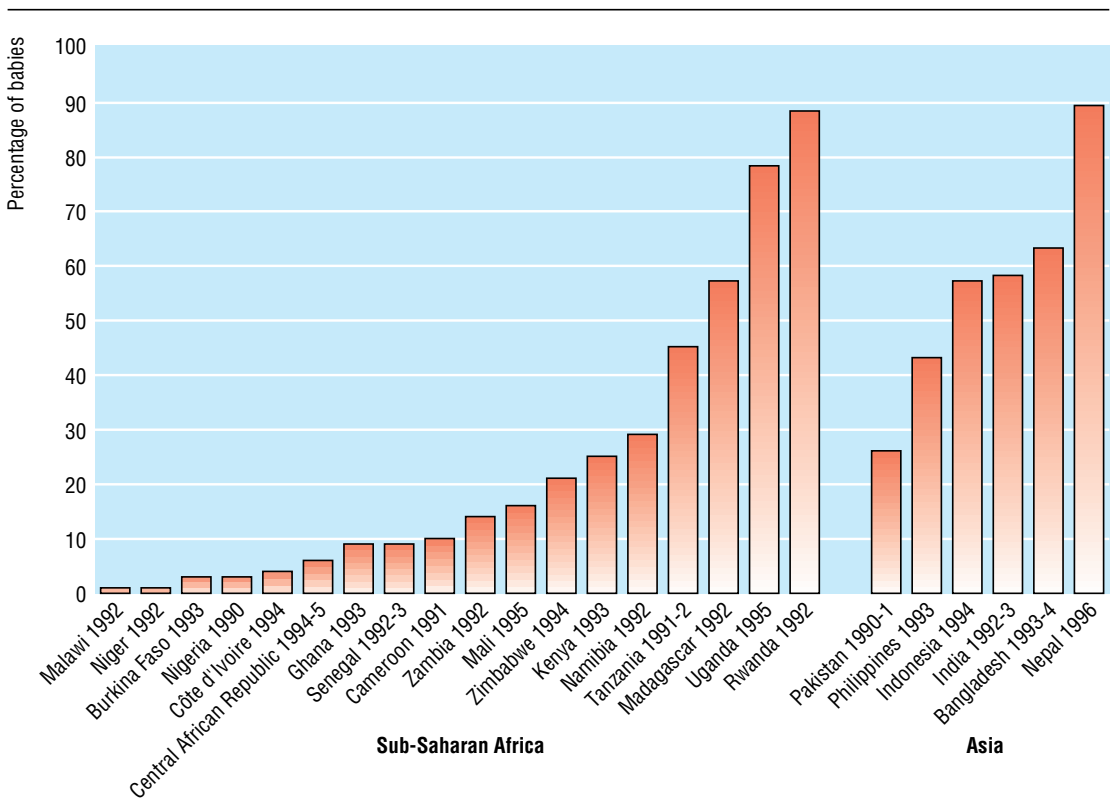

Prevalence of exclusive breast feeding of 1 month old babies in some African and Asian countries ${ }^{5}$ considerable problems, with extra laboratory and counselling services needed and the risk of a hostile community reaction. Maintaining long term prophylaxis even with effective drugs such as isoniazid and co-trimoxazole may also be difficult in more remote areas (as it is already with the treatment of other long term conditions such as hypertension and schizophrenia).

National HIV/AIDS programmes should be balanced in the needs of both the community and the individual, and in prevention and care. Patience is needed in effecting changes in the perceptions of a community in relation to HIV/AIDS, from panic and denial through to acceptance. This can be difficult in the face of so much death and suffering. Much remains to be done in improving access to information to empower poor people living in remote areas.

There is also an urgent need to improve access to condoms; strengthen health programmes such as directly observed treatment, short course (DOTS) for tuberculosis and the syndromic approach to sexually transmitted disease treatment; and improve practical support to communities caring for those who are sick and the orphans.

Much good will and money seems to be available, but this often does not reach where it is needed because of concerns regarding lack of sustainability, bureaucratic administration, and communication difficulties. Maybe no effective solution to the HIV/ AIDS epidemic will exist until a medical breakthrough is made, such as the development of a vaccine.

The epidemic has been around long enough for the effects to be obvious to people even in remote areas. This allows health workers to be more successful in confronting traditional beliefs, such as those about gender roles and traditional medicine, in prevention campaigns. All partners working with prevention programmes should maintain their momentum through what can sometimes seem a difficult damage limitation exercise. They should use the more positive community attitudes towards HIV/ AIDS issues seen in many sub-Saharan countries to develop evidence based programmes that focus more on improved access and less on sustainability.

Alex Manning general registrar

Burwell Surgery, Burwell, Cambridgeshire CB5 0AE

alex.sam@virgin.net

Competing interests: None declared.

1 Zwi K, Soderlund N, Schneider H. Cheaper antiretrovirals to treat AIDS in South Africa. BMJ 2000;320:1551-2. (10 June.)

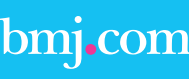

Rapid responses

Correspondence submitted electronically is available on our website 